\title{
Surgical treatment of atypical Mycobacterium intracellulare infection with chronic empyema: A case report
}

\author{
Kazutoshi Kotani, MD, Yoshinaru Hirose, MD, Shigeto Endo, MD, Hiroshi Yamamoto, MD, and
}

Shigeki Makihara, MD, Tsukubogun, Japan

A

typical mycobacterial infection in the patient with chronic empyema is very uncommon. We report a case of Mycobacterium intracellulare infection in a patient with chronic empyema treated successfully with surgical intervention.

\section{Clinical Summary}

On April 1, 2003, an 80-year-old woman was admitted to the hospital with a right pleural effusion. Chest radiography and chest computed tomographic scanning revealed a right thoracic effusion (Figure 1). $M$ intracellulare was isolated from the thoracic effusion and the sputum. The patient was diagnosed with an $M$ intracellulare infection with a chronic empyema and an alveolar fistula. She received drug therapy consisting of rifampin (INN: rifampicin), ethambutol hydrochloride, enviomycin sulfate, and clarithromycin and irrigation into a closed thoracic drainage tube.

On June 24, we performed a thoracic fenestration. The 8th, 9th, and 10th ribs were partially resected $(8 \mathrm{~cm})$. The patient received irrigation $(500 \mathrm{~mL}$ of saline) into the thoracic fenestration daily.

On October 15, we performed a thoracoplasty with an intrathoracic transposition of the muscle flap using the serratus anterior and the latissimus dorsi muscles (Figure 2). The 7th, 8th, 9th, 10th, and 11th ribs were resected. The 3 alveolar fistulas were closed with a mattress suture into the lung and injection of gelatin-resorcinformalin-glutaraldehyde (GRFG) glue into the alveolar fistulas.

On postoperative day 30 , the thoracic drainage tube was removed, and the empyema did not recur.

The patient will receive a drug regimen consisting of rifampicin, ethambutol hydrochloride, and clarithromycin for 1 year.

\section{Discussion}

A typical mycobacterial infections usually develop in the lung, and infection outside the lung is rare. ${ }^{1}$ Atypical mycobacterial infection in the patient with chronic empyema in particular is very uncommon. $^{2}$ The pathway of atypical mycobacterial infection to chronic empyema is unclear, but there are 2 theories about the

\footnotetext{
From the Department of Surgery, National Hospital Organization MinamiOkayama Medical Center, Tsukubogun, Japan.

Received for publication Dec 28, 2004; accepted for publication Feb 3, 2005.

Address for reprints: Kazutoshi Kotani, MD, Department of Surgery, National Hospital Organization Minami-Okayama Medical Center, 4066 Hayashimacho, Tsukubogun, 701-0304, Japan (E-mail: kk77@f7.dion.ne.jp).

J Thorac Cardiovasc Surg 2005;130:907-8

$0022-5223 / \$ 30.00$

Copyright $\odot 2005$ by The American Association for Thoracic Surgery doi:10.1016/j.jtcvs.2005.02.054
}

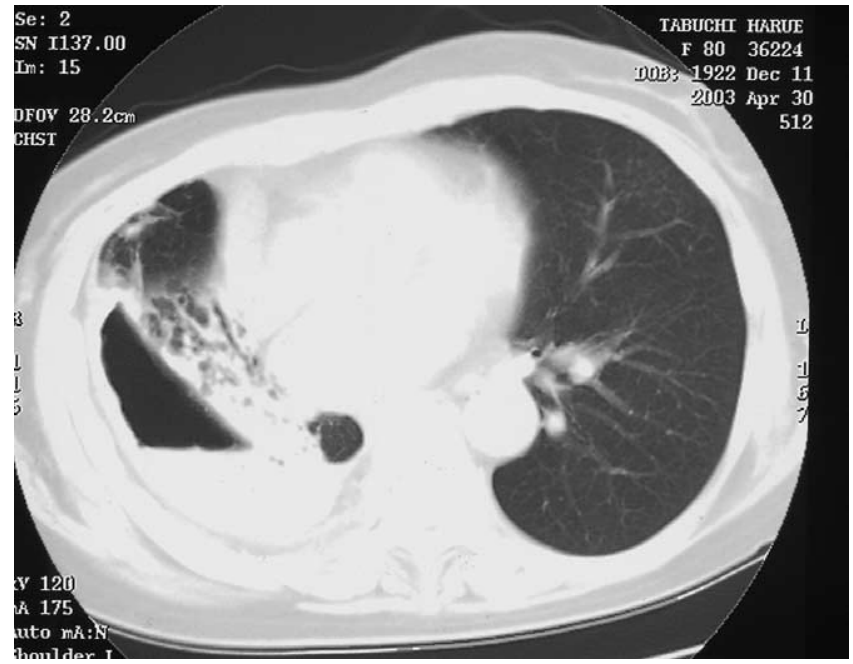

Figure 1. Chest computed tomographic scan showing a right thoracic effusion and honeycomb lung of the right middle and lower lobes.

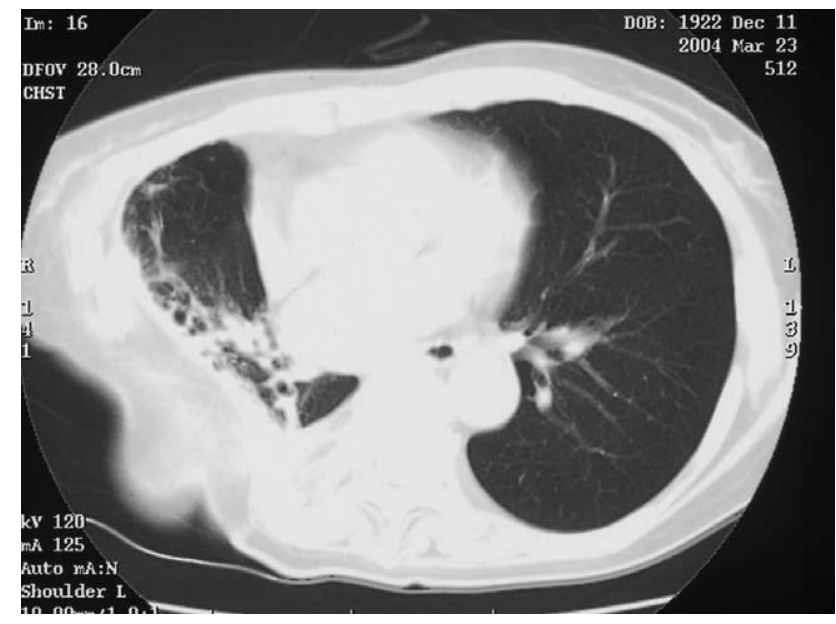

Figure 2. Thoracoplasty and an intrathoracic muscle flap transposition using the serratus anterior and the latissimus dorsi muscle were performed.

process. ${ }^{1}$ The first theory is development of the empyema from the lung infection. The second theory entails the development of the empyema after a minor trauma. 
The surgical management of $M$ intracellulare infection with chronic empyema is not established. Yamamoto and associates ${ }^{1}$ reported a case of Mycobacterium avium complex infection in a patient with a chronic empyema, which was treated successfully with pleuropneumonectomy. They stated that lung resection might be performed for the surgical treatment of $M$ intracellulare infection with chronic empyema. Pleuropneumonectomy or lobectomy for chronic empyema, however, is very stressful. In our case, the $M$ intracellulare infection was cleared from the sputum after thoracic fenestration, and therefore we performed a thoracoplasty with an intrathoracic muscle flap transposition. This surgical treatment without lung resection in cases not involving $M$ intracellulare in the sputum is preferred because the procedure is less invasive, safer, and less stressful than surgical treatment with lung resection.

In our case, we selected a thoracoplasty with an intrathoracic muscle flap transposition. The residual lung changed into a honeycomb lung, which was unable to expand. If the residual lung had the ability to expand, air plombage would have been a better option than thoracoplasty with respect to respiratory function. ${ }^{3}$

GRFG glue is a new biologic adhesive agent with a better sealing efficacy. GRFG glue has strong adhesive properties (al- most 5 times that of fibrin glue). Several studies have reported the effectiveness of GRFG glue for the treatment of bronchial fistulas. ${ }^{4,5}$ Hasumi and colleagues ${ }^{4}$ reported the clinical experience of GRFG glue for acute empyema with bronchopleural fistula. GRFG glue is a useful agent for the treatment of bronchial fistulas.

\section{References}

1. Yamamoto H, Osako T, Aogauchi R, Yamamoto H, Hironaka S. Surgical treatment of Mycobacterium avium complex infection in a patient with chronic empyema. Nippon Geka Gakkai Zasshi. 1994;95:123-5.

2. Takemoto N, Kohiyama R, Tsuboi J, Sasaki K, Sakurabayashi I, Miyata M. A case of a patient with post-operative empyema due to Mycobacterium chelonae. Kyobu Geka. 1996;49:301-5.

3. Otsuka T, Imura Y, Yamamoto H, Sasano S. One case of chronic pyothorax with MRSA infection cured by air-plombage method. Kekkaku. 1999;74:513-7.

4. Hasumi T, Yamanaka S, Yamanaka H. Clinical experience of gelatinresorcin-formal (GRF) glue for acute empyema with broncho-pleural fistula. Kyobu Geka. 2003;56:82-5.

5. Umemori Y, Makihara S, Fukuhara T, Kotani K, Eda R. An effective case of a new biological adhesive agent, gelatin-resorcinol formaldehyde-glutaraldehyde glue (GRFG-glue) in treating refractory pulmonary fistula following lobectomy for pulmonary aspergilloma. Kyobu Geka. 1999;52:872-4.

\title{
Simultaneous traumatic rupture of bilateral pulmonary hydatid cysts
}

\author{
Berkant Özpolat, MD, ${ }^{\text {a }}$ Murat Sayın, MD, ${ }^{\text {b }}$ Orhan Veli Dogan, MD, ${ }^{a}$ and Yusuf Dogan, MD, ${ }^{\mathrm{b}}$ Ankara, Turkey
}

$\mathrm{H}$ ydatid disease is common in Turkey, and it is a serious problem of worldwide importance. Because of the elastic properties of the lung, it seldom shows signs and symptoms. The cysts are generally detected on routine examinations incidentally or when they are complicated. All hydatid cysts carry a risk of rupture, which is the most common complication, and trauma is a one of its causes. ${ }^{1,2}$

Here we present a life-threatening complication of traumatic bilateral ruptured hydatid cysts causing simultaneous bilateral pneumothorax. To our knowledge, this bilateral rupture is the first case reported in the English literature.

\footnotetext{
From the Departments of Cardiovascular Surgery ${ }^{\mathrm{a}}$ and Anesthesia and Reanimation, ${ }^{\mathrm{b}}$ Ministry of Health Diskapi Training and Research Hospital, Ankara, Turkey.

Received for publication March 3, 2005; accepted for publication March 28, 2005.

Address for reprints: Orhan Veli Dogan, MD, Esat Caddesi 105/14, Küçükesat 06660, Ankara, Turkey (E-mail: orhanv@yahoo.com).

J Thorac Cardiovasc Surg 2005;130:908-9

$0022-5223 / \$ 30.00$

Copyright $\odot 2005$ by The American Association for Thoracic Surgery

doi:10.1016/j.jtcvs.2005.03.028
}

\section{Clinical Summary}

A 20-year-old man was brought to the emergency department after a vehicle accident. He had diminished bilateral breath sounds and diffuse bronchospasm on auscultation. He was cyanotic and severely dyspneic. The computed tomographic (CT) scan of the thorax performed at the emergency department revealed bilateral pneumothorax and bilateral linear fibrotic densities in both lungs (Figure 1).

Bilateral chest tube insertion was performed immediately. After tracheal intubation, mechanical ventilation was started because of acute respiratory failure. The patient was transferred to the intensive care unit, and the mechanical ventilation was continued for 2 days. Steroid therapy was given to relieve the bronchospasm. After the expansion of both lungs, a new CT scan was performed, showing thin-walled, air-filled cavities in bilateral lobes with collapsed membranes that were specific for ruptured hydatid cysts (Figure 2). Serologic test results for hydatid disease were positive.

Chest tubes were removed at the 10th and 14th days after the expansion of both lungs, and the patient was discharged on the 17 th day. Albendazole $\left(10 \mathrm{mg} \cdot \mathrm{kg}^{-1} \cdot \mathrm{d}^{-1}\right)$ therapy was started as soon as the rupture was diagnosed, and it was continued for 6 months. No cavitary or pleural complications were observed at the 6-month examination. 